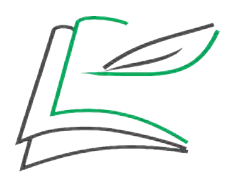

Entretextos

Entretextos 20(2):199-206; jul./dez. 2020

ISSN $1519-5392$

DOI: $10.5433 / 1519-5392.2020 v 21 \mathrm{n} 2 \mathrm{p} 199$

\title{
Entrevista com professora Ana Elisa Ribeiro
}

\author{
Interview with teacher Ana Elisa Ribeiro \\ Entrevista con profesora Ana Elisa Ribeiro
}

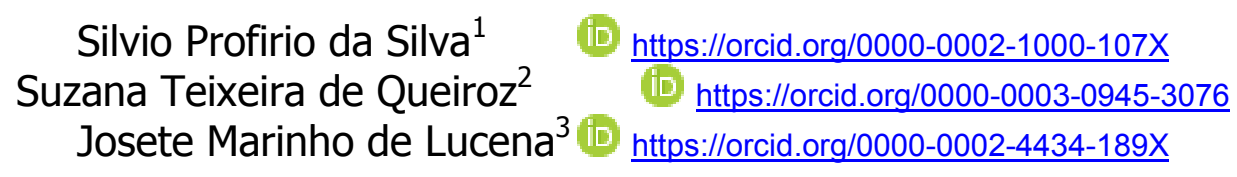

RESUMO: O contexto estimulado pela presença das tecnologias digitais nas rotinas educacionais tem impulsionado novos moldes educacionais, cujo cerne está na apropriação do saber e, sobretudo, na autonomia do discente nesse processo de construção. Diante desse contexto, em vez de primar pela recepção mecânica de conteúdos, as situações didáticas têm investido cada vez mais na perspectiva da mediação, ou seja, a ação de estimular e auxiliar o discente no processo de construção do saber. Tendo como pano de fundo esse contexto paradigmático, cada vez mais, as unidades de ensino têm fomentado situações didáticas amparadas nas tecnologias digitais. O objetivo disso é estimular não apenas novos moldes de ensino, mas, sobretudo, novos moldes de construção da aprendizagem e novas posturas do discente frente ao saber. Neste trabalho, apresentamos os resultados de uma entrevista realizada com a Professora Ana Elisa Ribeiro sobre os reflexos da disseminação das redes de comunicação e da internet nas rotinas educacionais.

PALAVRAS-CHAVE: Artefatos tecnológicos e digitais. Disseminação. Contexto educacional.

ABSTRACT: The context stimulated by the presence of digital technologies in educational routines has driven new educational patterns, whose core is in the appropriation of knowledge and, above all, in the autonomy of the student in this construction process. Given this context, instead of focusing on the mechanical reception of content, didactic situations have increasingly invested in the perspective of mediation, that is, the action of stimulating and assisting the student in the process of building knowledge. With this paradigmatic context as a backdrop, more

\footnotetext{
${ }^{1}$ Mestre pelo Programa de Pós-Graduação em Linguística e Ensino da Universidade Federal da Paraíba UFPB. Professor de Língua Portuguesa na Prefeitura de Vitória de Santo Antão. E-mail: profirio.silvio@bol.com.br

2 Mestra em Educação, Culturas e Identidades pela Universidade Federal Rural de Pernambuco - UFRPE. Professora na Prefeitura da Cidade do Recife, bem como na Prefeitura da Cidade de Paulista. E-mail: queiroz.suzana@yahoo.com.br

3 Doutora em Linguística pela Universidade Federal do Ceará - UFC. Professora Adjunta na Universidade Federal da Paraíba - UFPB. E-mail: josetemarinho.ufpb@gmail.com
} 


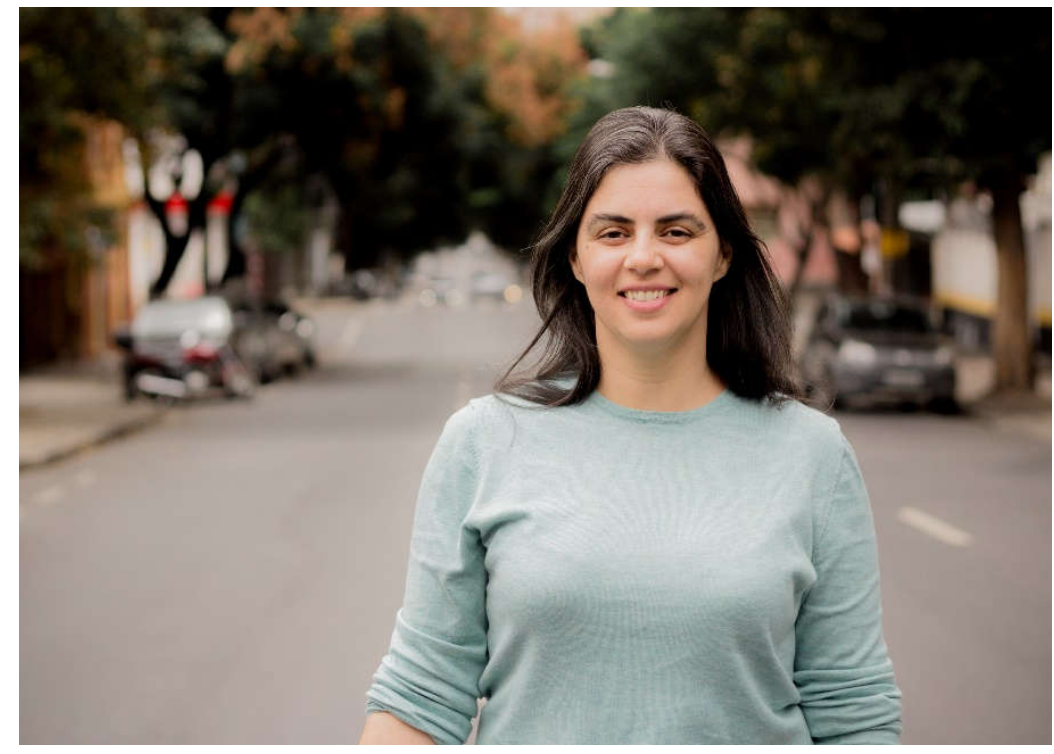

Fonte: Ana Elisa Ribeiro (2019). ${ }^{4}$

\section{Perguntas}

\section{Silva; Queiroz; Lucena - Quais os reflexos da propagação das tecnologias digitais no trabalho pedagógico do ensino de língua materna? Como o professor de língua pode fazer usos dessas ferramentas no seu trabalho pedagógico?}

Ana Elisa Ribeiro - As tecnologias digitais, em muitos dispositivos diferentes, chegaram há algumas décadas e se instalaram. Como tudo na vida, a sala de aula e o ensino também sentiram o impacto dessa chegada. São muito amplos os usos possíveis desses artefatos. Estamos falando de quê? Computadores, smartphones, aplicativos, datashows? Há uma infinidade de coisas, de portes diferentes, que chamamos de TDICs (Tecnologias Digitais de Informação e Comunicação). Desde o hardware ao software. É possível dar aulas usando um PowerPoint numa máquina e projetando na parede até fazer algo bem mais complexo, como operar um software na nuvem com estudantes, remotamente, como ocorre ao Google Docs, por exemplo, ou qualquer outro. O professor só precisa estar inserido socialmente, porque os usos das tecnologias digitais são aprendidos socialmente e, depois, passar a pensar em "traduções" para a sala de aula. Não sei se a metáfora é boa, mas é preciso pensar criativamente na transposição ou em modos de ensinar que possam se fazer valer de dispositivos para ajudar a ampliar e ir além. Não

\footnotetext{
${ }^{4}$ Créditos da imagem: Adamo Alighieri.
} 
acho que o uso de TDICs deva acontecer a todo custo. Acho que há usos pertinentes a elas. E eles são muitos e diversos.

\section{Silva; Queiroz; Lucena - Quais os reflexos dos postulados atinentes às tecnologias digitais nos cursos de formação de professores?}

Ana Elisa Ribeiro - Os cursos de formação de professores estão no mundo, estamos todos afetados pelo que ocorre à vida social. Temos de falar em tecnologias digitais e em tecnologias passadas para aqueles que se formam para serem professores. O negócio nem é exatamente ficar apresentando tecnologias que todos conhecemos, mas tratar dos usos que podemos fazer delas, para fins específicos, tais como: ensinar determinado ponto de aula. Isso cada um precisa saber pensar e/ou fazer e, às vezes, coletivamente. Os cursos de formação têm esse compromisso. Formar professores é formar professores para o presente e o futuro, não é isso?

\section{Silva; Queiroz; Lucena - Qual a diferenciação entre letramento e multiletramentos?}

Ana Elisa Ribeiro - Essa é uma diferença que está na bibliografia da área. O que eu disser, aqui, será muito barateado, muito resumido. O letramento é a noção chegada ao Brasil, segundo dizem estudos, nos anos 1980, a partir de discussões estrangeiras, mas nos coube bem. Muito rasamente, seriam as práticas sociais de leitura e escrita, o que as pessoas fazem com essas competências. Já nos anos 1990, pesquisadores estrangeiros reunidos nos Estados Unidos propuseram, num manifesto, os multiletramentos, que levariam em conta a multiplicidade de linguagens e de culturas dos cidadãos e cidadãs que usam socialmente a leitura e a escrita, de diversos modos e em variados contextos. Essa ideia foi muito difundida no Brasil pela Angela Dionísio, de Pernambuco, e pela Roxane Rojo, de Campinas, SP. Multiletramentos quer ser mais amplo do que letramento. Talvez nem precisássemos, se tivéssemos entendido que as práticas sociais são "relativamente estáveis", tomando emprestado de Bakhtin. 
4. Silva; Queiroz; Lucena - Em virtude da disseminação das tecnologias digitais, nos últimos anos, os trabalhos atinentes à multimodalidade discursiva propagaram-se de maneira considerável. Como a senhora conceitua a multimodalidade discursiva e os textos multimodais?

Ana Elisa Ribeiro - Também é difícil tratar disso em poucas linhas. Começo dizendo o que os autores mais evidentes da sociossemiótica dizem: todo texto é multimodal. E sempre foi, como podemos desconfiar. Nesse sentido, não há novidade. As teorias, isto é, as lentes por onde ver é que nos soaram como novidades e aí danamos a falar como se os textos pudessem ter sido monomodais algum dia. As tecnologias digitais mudaram muitos textos e até deram chance a que outros fossem inventados. Talvez não conhecêssemos, antes da Internet, os e-mails (mesmo sendo, eles, parentes das cartas) e nem os memes, como os temos hoje. Mas atentar para a multimodalidade, com esse nome, é o que os pesquisadores vêm fazendo. Isso amplia, de fato, nossa noção de texto, de edição, de leitura. Acho que só pode ser bom. Textos multimodais são todos, isto é, qualquer texto que circule a partir de modos diversos, ou melhor, a natureza dele, sua composição, é feita de vários modos, modulados, conforme um efeito que se deseje, e assim eles circulam. E, na camada da circulação, eles ainda ganham mais sentidos em novos modos. Tudo é produzido dessa maneira.

\section{Silva; Queiroz; Lucena - Como os textos multimodais contribuem para a formação de leitores competentes e proficientes?}

Ana Elisa Ribeiro - Não sei se é isso ou o contrário: os leitores contribuem para a leitura dos textos. Os leitores competentes lidam bem com textos. E se todo texto é multimodal, teremos aí apenas uma questão de nível, de grau, de complexidade menor ou maior. Do ponto de vista do ensino, o contato com textos diversos pode ajudar na formação de leitores mais versáteis. 


\section{Silva; Queiroz; Lucena - Como o professor pode inserir os textos multimodais nas rotinas educacionais? Quais elementos constitutivos devem ser enfatizados?}

Ana Elisa Ribeiro - Todo texto sendo multimodal essa questão se enfraquece. Os professores já fazem isso. Só que podem fazer mais, melhor. Talvez não façam à luz desta teoria, meio sem saber. Mas se quiserem trabalhar sob esse ângulo, poderão levar para a sala de aula textos muito diversos, menos e mais complexos, e traçar análises que pensem sobre a produção, as linguagens componentes, os modos de ler, as camadas de sentido etc. É tão interessante e está sob nossos narizes. Muitos textos que todos lemos podem ser assim analisados, tornados objetos de estudo.

\section{Silva; Queiroz; Lucena - Como a senhora conceitua a leitura e/ou processamento textual?}

Ana Elisa Ribeiro - Mais uma pergunta difícil de resumir. Há infinitas definições de leitura e muitos modelos para explicar o processamento do texto quando lemos. Posso baratear, dizendo que podemos enxergar a leitura como um processo mental e individual; ou podemos pensá-la como uma prática social. Isso muda o escopo e o âmbito. Tenho preferido pensar nas práticas sociais há alguns anos, mas já trabalhei com a parte cognitiva. Todas, porém, são importantes e precisam ser compreendidas.

\section{Silva; Queiroz; Lucena - 0 que é o hipertexto? Quais suas características, particularidades e especificidades?}

Ana Elisa Ribeiro - Difícil também! O hipertexto já foi estudado e reestudado, em especial, na virada do milênio, quando estávamos todos meio perplexos com os textos meio fragmentários que a web nos apresentava. Por alguns, o hipertexto foi tratado como esse texto dividido, conectado por meio de links e nós acessamos, dando cliques e zanzando. Como se o hipertexto só existisse nas telas, na web. Outros, que considero mais ponderados, trataram logo de dizer que o hipertexto já existia no papel, nos textos também divididos em nós, que nos fazem passear daqui para ali. Na literatura, então, eles existiram em profusão e até foram meio proféticos. Hoje em dia, o tema está mais 
arrefecido. Acho que a polêmica maior passou. Mas os hipertextos continuam aí, como sempre estiveram. O específico do hipertexto, para mim, é ele ser internamente conectado, desconectado, nodal. $\mathrm{O}$ ambiente não é o que o torna mais específico. Mas alguns ainda podem defender outra coisa.

9. Silva; Queiroz; Lucena - Diante do lastro da propagação dos suportes hipertextuais presentes nas práticas do dia a dia, quais as modificações ocorridas na leitura? Quais as particularidades e as especificidades desse novo formato de leitura?

Ana Elisa Ribeiro - Essa relação entre leitura e ambientes foi muito estudada e ainda é. Muita gente se perguntou o que aconteceria à leitura, caso os textos fossem mais fragmentários. Minha dissertação e minha tese tratam disso, em especial, nos jornais, que são mosáaiquicos há muito. As práticas de leitura mudaram no sentido de se ampliarem. Há mais modos de ler hoje, mas se misturaram a alguns mais antigos também. A leitura exigiu mais das pessoas. Ler em papel e ler nas telas, fazer cliques mais evidentes, desconfiar mais do que se lê, de onde vem. Os filtros foram subvertidos. Aprendemos a fazer melhor e a ler com menos tempo. Muita coisa aconteceu. Mas continua sendo importante aprender a ler bem.

10. Silva; Queiroz; Lucena - Diante do amplo contingente de gêneros digitais, dos suportes hipertextuais e das mídias audiovisuais presentes nas atividades cotidianas, quais as novas competências requeridas do alunado e dos sujeitos inseridos nas práticas sociais, no que se refere à leitura?

Ana Elisa Ribeiro - Não se trata apenas de competências do alunado. Todos têm de lidar com a leitura e a escrita em ambientes mais recentes, não é? Há mais recursos, mais textos em circulação evidente, as competências se aprofundaram ou diversificaram (prefiro essa palavra, sabe?) e estivemos não apenas incluídos, como se fôssemos passivos e apenas tivessem nos colocado em um seleto grupo; nós fomos parte dessa mudança. Socialmente, nós inventamos, usamos e reinventamos muitas coisas, sem ser exatamente especialistas ou doutores em nada. As práticas cotidianas são isto: cotidianas. Quando temos um smartphone e baixamos um aplicativo de paquera ou de mensagens, 
estamos nos dando novas chances de linguagem e vamos aprender e ser aprendidos, com nossos modos de ler e escrever. É muito legal que isso esteja ocorrendo a olhos vistos! Não somos inseridos nas práticas sociais. Nós fazemos essas.

\section{Referências}

LEVY, Pierre. Cibercultura. São Paulo: Editora 34, 1999.

MORAN, José. Novas tecnologias e mediação pedagógica. Campinas, SP: Papirus, 2013.

\section{Biografia da entrevistada}

Ana Elisa Ribeiro possui Mestrado e Doutorado em Linguística, bem como Pós-doutorado em Comunicação, Linguística Aplicada e Estudos Literários. Desde o início dos anos 2000, atua no âmbito da docência de Língua Portuguesa e Literatura, além de atuar no contexto da edição de textos. Desde 2006, é docente do Centro Federal de Educação Tecnológica de Minas Gerais (CEFET-MG). É pesquisadora no contexto da Linguística Aplicada, focando nas seguintes temáticas: tecnologias e rotinas educacionais, leitura e escrita no suporte do hipertexto, multimodalidade discursiva, textos multimodais e ensino de língua etc. Além disso, é p oetisa, tendo publicado produções literárias. 